\title{
The economic impact of Mexico City's smoke-free law
}

\author{
Carlos Manuel Guerrero López, ${ }^{1}$ Jorge Alberto Jiménez Ruiz, ${ }^{1}$ \\ Luz Myriam Reynales Shigematsu, ${ }^{1}$ Hugh R Waters ${ }^{2}$
}

1 Department for Tobacco Research, Population Health Research Center, National Institute for Public Health, Cuernavaca, Morelos, Mexico, USA

${ }^{2}$ Department of Health Policy and Management, Johns Hopkins Bloomberg School of Public Health, Johns Hopkins University, Baltimore, Maryland, USA

\section{Correspondence to}

Dr Hugh R Waters, Departments of Health Policy and

Management and Health, Behavior, and Society, Johns Hopkins Bloomberg School of Public Health, Rand Health, 1776 Main Street, Room 4369, Santa Monica, CA 90401-3208, USA; waters@rand.org

Received 24 February 2010 Accepted 21 December 2010 Published Online First

3 February 2011

\section{ABSTRACT}

Objective To evaluate the economic impact of Mexico City's 2008 smoke-free law-The Non-Smokers' Health Protection Law on restaurants, bars and nightclubs.

Material and methods We used the Monthly Services Survey of businesses from January 2005 to April 2009 — with revenues, employment and payments to employees as the principal outcomes. The results are estimated using a differences-in-differences regression model with fixed effects. The states of Jalisco, Nuevo León and México, where the law was not in effect, serve as a counterfactual comparison group.

Results In restaurants, after accounting for observable factors and the fixed effects, there was a $24.8 \%$ increase in restaurants' revenue associated with the smoke-free law. This difference is not statistically significant but shows that, on average, restaurants did not suffer economically as a result of the law. Total wages increased by $28.2 \%$ and employment increased by $16.2 \%$. In nightclubs, bars and taverns there was a decrease of $1.5 \%$ in revenues and an increase of $0.1 \%$ and $3.0 \%$, respectively, in wages and employment. None of these effects are statistically significant in multivariate analysis. Conclusions There is no statistically significant evidence that the Mexico City smoke-free law had a negative impact on restaurants' income, employees' wages and levels of employment. On the contrary, the results show a positive, though statistically non-significant, impact of the law on most of these outcomes. Mexico City's experience suggests that smoke-free laws in Mexico and elsewhere will not hurt economic productivity in the restaurant and bar industries.

\section{INTRODUCTION}

There is now a broad international scientific consensus that exposure to secondhand smoke (SHS)-also called environmental tobacco smoke-is an important risk factor that can cause serious damage to human health, as summarised in the 2006 US Surgeon General's Report ${ }^{1}$ and related scientific literature. Governments are responding to this evidence by adopting measures to restrict smoking in public places and to limit exposure to SHS. Many of these measures are compatible with the commitments made by the signatories of the Framework Convention on Tobacco Control (FCTC), which as of June 2010 has been signed by 168 countries and ratified by $148 .^{2}$ Mexico signed and ratified the FCTC in 2004.

Article 8 of the FCTC requires signatories to adopt and implement measures to protect their populations from exposure to SHS in indoor workplaces, public transportation and closed public spaces. ${ }^{3}$
However, for countries and municipalities contemplating a ban on smoking in public places, the potential negative economic impact of such a ban remains a concern. In many countries, the hospitality industry-representing the interests of restaurants and bars-has funded studies to show that smoking bans will harm their economic interests, and by extension overall employment and economic productivity. Studies funded by the National Restaurant Association in the USA-and similar bodies at the state level in Maryland and Ohio, Ontario Province in Canada and the state of New South Wales in Australia-have found decreases in income and overall sales, particularly for alcohol, following the implementation of smoking bans. ${ }^{4-6}$

In contrast to the findings of these industrysponsored studies, peer-reviewed research has generally shown relatively small impacts on employment and revenues in the hospitality sector-including restaurants, pubs and bars. Overall, a review of 97 studies of the impact of smoking bans on the hospitality industry, published in 2003 , found that that $94 \%$ of studies supported by the tobacco industry found a negative economic impact of smoking bans, compared to none of non-industry supported studies. ${ }^{8}$

At the national level, studies in Canada, ${ }^{9}$ New Zealand $^{10}$ and Hong Kong ${ }^{11}$ show that bans on smoking in bars, clubs and restaurants led to constant or increasing trends in revenues and employment. Similarly, a study in the state of Tasmania in Australia used seasonally adjusted monthly sales to evaluate the economic impact of a law mandating smoke-free public places implemented in 2001, finding that the law had no impact on sales in pubs relative to overall retail sales in the state. $^{12}$ A 2006 study in Scotland, using a quasiexperimental difference-in-difference design, did find a negative impact of a smoking ban on pub sales and number of customers, compared to similar cities in northern England where a smoking ban had not been implemented. ${ }^{13}$

A 2004 review of the effect of smoke-free policies on the sale price of restaurants in affected jurisdictions in the USA found that smoke-free legislation was associated with a median increase of $16 \%$ in the sale price-compared to jurisdictions without such legislation. ${ }^{14}$ In the state of California in the USA, bans on smoking in restaurants (in 1995) and bars (1998) have been shown to have positive effects on both restaurant and bar revenues. ${ }^{15-17}$ A 1998 study in the state of Arizona in the USA used sales as the key outcome measure, and found that the smoking ban in that state did not have negative effects on sales in restaurants. ${ }^{18}$ unlocked scheme, see http// about/unlocked.xhtml 
A study in the state of Massachusetts in the USA, covering the time period 1992-1998, used a before and after quasiexperimental design to compare tax revenues before and after the implementation smoking banks in specific communities in the state, while non-adopting communities were used as counterfactual. That study found that smoking restrictions were associated with a $3.7 \%$ annual increase in tax revenues. ${ }^{19}$ In the 9 months following the March 2003 implementation of a smoke-free policy for restaurants and bars in New York City, employment in restaurants and bars increased by 10600 jobs and taxable receipts rose by $9 \%{ }^{20} 21$

A 2009 report prepared by the International Agency for Research on Cancer (IARC) of the World Health Organization takes a comprehensive look at the costs and benefits resulting from smoke-free laws-including improved productivity from fewer smoking breaks; lower insurance premiums and lower costs for cleaning, maintenance and potential litigation. The IARC report identified a total of 165 studies of the economic impact of smoke-free policies; 49 of these were considered methodologically sound. Forty-seven of these 49 studies concluded that the policies had either no economic impact or a positive economic impact on the hospitality industry. ${ }^{22}$

However, compared with the evidence now available in highincome countries, there is still not much documentation of the economic impact of smoke-free laws in low and middle-income countries. Research in South Africa, using provincial-level panel data with value-added tax (VAT) receipts as a measure of restaurant sales, has shown that the 1999 Tobacco Products Control Amendment Act concluded that the legislation has not hurt the restaurant business. Overall, 59\% of restaurants had no change in revenue, while $22 \%$ had higher sales and $19 \%$ had a decrease in sales. Franchised restaurants as a group had increased sales, while independent restaurants showed a slight decrease on average. ${ }^{23} 24$

In Latin America, Uruguay has a nationwide law in effect since March 2006. Several provinces of Argentina have implemented bans on smoking in public places since mid-2006. In 2009, Sao Paulo in Brazil became a smoke-free city. To date, however, there is little documentation of the economic impact of such legislation in the Latin American region. One unpublished study in Uruguay, using a time series analysis approach, shows that the law had a statistically insignificant negative impact of $-0.14 \%$ on sales in restaurants and bars, with sales proxied by VAT receipts (Ramos A, unpublished, 2009).

In Mexico, according to the 2004 economic census (the most recent available), there were approximately 83500 restaurants and bars-employing 466500 workers and accounting for $1.9 \%$ of the country's businesses. ${ }^{25}$ In February 2008 the Legislative Assembly of the Federal District, which encompasses Mexico City, approved the Protection of the Health of Non-Smokers Act (Ley de Protección a la Salud de los No Fumadores). This law, which took effect in April 2008, prohibits smoking in enclosed public spaces, defined as restaurants, bars, taverns and other commercial establishments in which natural air does not circulate in a free manner. Windows, doors, ventilators and other openings in a building's physical structure are not considered to be spaces for the free movement of air. Open spaces and terraces are defined as spaces without a roof. In addition, the law forbids smoking in public vehicles and taxis driving in the Federal District. $^{26}$

In August 2008 a nationwide law, the General Law for Tobacco Control was passed. This law, which was not implemented until May 2009 following the publication of its governing regulations, bans smoking in indoor workplaces and enclosed public spaces-including offices, schools, hospitals and in public transportation. ${ }^{27}$ The federal law, as originally published in $2008,{ }^{28}$ required separate spaces for smoking. However, a revision published in January 2010 changed the text to read that 'In places with public access, or in internal areas of employment, there may be spaces reserved for smoking, as long as these areas conform to existing regulations.' The federal law is considered as a floor in terms of regulations and does not override state or local regulations, such as the Mexico City law. ${ }^{29}$

The objective of the current study is to evaluate the economic impact of Mexico City's 2008 smoke-free law-'The NonSmokers' Health Protection Law'-on restaurants, bars and nightclubs, in terms of revenues, wages and employment. Because the federal law was not implemented until May 2009, it is not considered as a confounder for our study, which covers the time period January 2005 to April 2009.

\section{METHODS}

We use a quasi-experimental, differences-in-differences estimation procedure to measure the impact of the Mexico City law. This approach seeks to measure the potential impact of unmeasured factors, and to answer the question, "What would the outcomes have been in the post-period in the absence of the policy?' The real impact of the policy change should be the difference between this counterfactual outcome and the actual observed outcome. The quasi-experimental design uses counterfactual areas, similar to Mexico City in terms of key characteristics but not exposed to the law, as a control group to estimate the counterfactual outcome.

In figure 1 , line A shows a hypothetical difference measured over time in the observed intervention group-equivalent in our case to bars and restaurants in Mexico City. Line B represents the behaviour of the variable of interest in the counterfactual group. Line $\mathrm{C}$ estimates how outcomes for group A would have in the absence of the intervention. In this case, the real effect of the intervention is the difference between line $\mathrm{A}$ and line $\mathrm{C}$

The model to estimate the average impact on businesses in the treatment group is as follows:

$$
\ln \left(y_{s t}\right)=\alpha_{s}+\lambda_{t}+\beta_{0} T_{t} P_{s}+\varepsilon_{s t}
$$

where $\ln \left(y_{s t}\right)$ is the natural logarithm of the outcome variable; T is a dichotomous variable indicating whether the business is in the treatment group; $\mathrm{T}=1$ if the business is in the treatment group (in Mexico City) and $\mathrm{T}=0$ otherwise. $\mathrm{T}$ is an indicator of the observation month and $\mathrm{s}$ refers to specific business. $\mathrm{P}_{\mathrm{s}}$ is an indicator variable for the time period-taking on the value

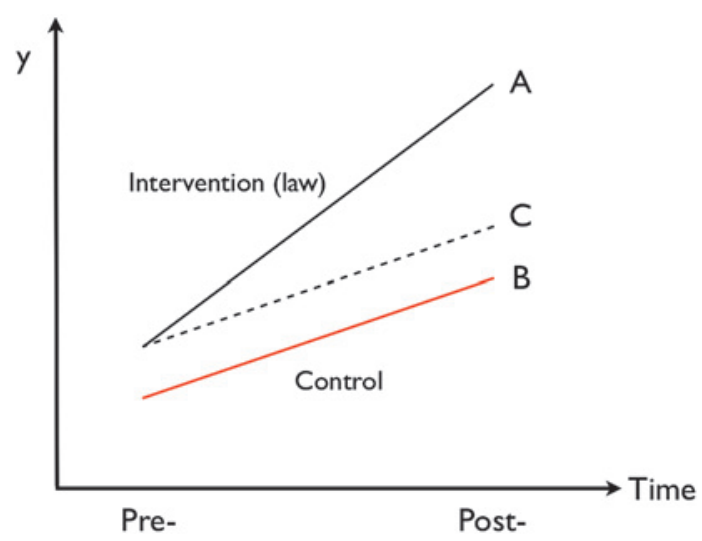

Figure 1 Quasi-experimental pre-post methodology. 
of 1 in the intervention time period (April 2008 to April 2009) and 0 otherwise.

In our model, $\beta_{0}$ is the impact estimator for the interaction between the variable indicating treatment group and the period of treatment; the semi-elasticity based on this coefficient tells us the magnitude of the impact of the law. Semi-elasticity is the percentage change in $y$ when $x$ increases by one unit. This is equivalent to the value of the $\beta$ coefficient when the dependent variable is in $\log$ form and the independent variable is not. However, in the case where the dependent variable is in form log $(y+1)$, the semi-elasticity is not equal to $\beta$ and must be calculated algebraically.

Fixed effects at the level of the specific business $(\alpha)$ control for underlying differences between the businesses; and fixed effects for time period $(\lambda)$ control for factors changing over time that affect all businesses regardless of the effect of the law. $E$ is the error term. The model assumes a constant treatment effect over the full period of treatment. ${ }^{30}$

The outcome variables analysed were the natural logarithm of revenues per day worked, wages per day worked and total employment in restaurants with waiters, nightclubs, bars and pubs. The estimation is calculated using ordinary least squares with fixed effects, correcting for serial correlation of the error terms at the level of the specific business. We also estimated models including fixed effects and the per capita gross domestic product (GDP) at the state level, but did not include these variables in the final model as they did not have a statistically significant effect.

In the regressions in this article, we estimated standard errors at the level of a specific business as a cluster, in order to avoid the problem that a difference-in-difference estimation that uses a large number of time periods could underestimate the standard errors when the outcome variables are serially correlated. ${ }^{31}$ The estimation of the impact of the law uses financial outcomes corrected for inflation using the National Index of Consumer Prices and April 2009 as the base month.

We chose a counterfactual group comprised the states of Jalisco, Nuevo León and México (different from Mexico City). These three states are similar to Mexico City in terms of demographic characteristics, but were not affected by the law passed in Mexico City in 2008. Smoking prevalence among adults aged $18-65$ years in these states, as measured in the 2008 National Addictions Survey, was 20.8\%, 26.5\% and 23.5\%, respectively-compared to $28.4 \%$ in Mexico City. ${ }^{32}$ At 172600 pesos, income per capita in 2008 was higher in Mexico City than in any other state in Mexico. It was 151500 pesos in Nuevo Leon, 81400 pesos in Jalisco and 54300 pesos in Mexico State. ${ }^{33}$

\section{Data}

The principal data source is the Monthly Services Survey, collected by the National Institute for Statistics and Geography (INEGI in Spanish). This survey is designed to provide ongoing data concerning economic trends in service industries in Mexico and to provide input into the national accounts system. It uses a probabilistic sampling design, with the 2004 economic census as a sampling frame, and includes data on revenues, expenses, wages, days worked and employment positions.

Our study uses monthly data from January 2005 to April 2009-including 39 monthly observations prior to the implementation of the law in April 2008, and 13 observations afterwards. January 2005 is the date that the Monthly Services Survey began operations. The categories of businesses included in our study are restaurants with waiters, nightclubs, bars and taverns-corresponding to the types of businesses affected by the Mexico City law.

The survey sample in Mexico City includes 47 restaurants with waiters and nine nightclubs, bars and taverns. Within each of these categories, the survey sample design incorporates statistical representativeness for key factors, including the size of the business. For the first category-restaurants with waiters $-49.1 \%$ of the sampled businesses are defined as microbusinesses or small businesses, $29.6 \%$ are medium sized and $21.3 \%$ are large companies. For nightclubs, bars and taverns, $87.8 \%$ are either micro-businesses or small businesses. In the services sector, a business with less than 11 employees is considered a microbusiness; small businesses are those with 11-50 employees; 51-100 employees constitutes a medium business; and $100+$ employees a large business. ${ }^{34}$

The sample in the counterfactual areas-the states of Jalisco, México and Nuevo León-consists of 19 restaurants with waiters and nine nightclubs, bars and taverns. For restaurants with waiters, $55.8 \%$ are micro-businesses or small businesses, $18.9 \%$ are medium sized and $26.3 \%$ are large companies. All of the nightclubs, bars and taverns are either micro-businesses or small businesses.

The key outcome variables included in the survey and used for this study include the following:

Income derived from economic activity-includes income from services and sales delivered to customers and other income, excluding returns on financial investments, donations, subsidies and the sale of capital goods.

Wages-includes salaries and other benefits paid directly to staff and social security benefits.

Total employment-includes individuals paid under a social security regime; casual employees not paid a base salary linked to social security; and owners, family members and other nonreimbursed employees.

A potential concern relates to selection bias in missing observations. If businesses fall out of the sample over time in way that is non-random with respect to the key explanatory variables, the results of the study would be expected to be biased. This could happen if restaurants, bars and nightclubs that were adversely affected by the smoking ban were more likely to close than other establishments and thus more likely to fall out of the sample from one year to the next. The estimation of the model presented includes all of the establishments that had missing outcomes for one or more time periods. We asked INEGI about the reasons for missing data and found that there is only one restaurant that closed in our sample and belongs to the counterfactual set.

This finding fits with observations from the National Institute for Statistics and Geography (INEGI in Spanish), the institution that conducts the survey, that the underlying reasons for changes in participation in the survey have to do with labour policy (paying hourly vs fixed salaries), emergency factors related to the influenza epidemic or spikes in income related to special events-all factors that would not be expected to influence the effects of the smoking ban.

Because we found only one restaurant that closed, we cannot estimate the impact under two step model and we agree that the measurement for these missing data should be zero during the period of closure. We re-estimated the models for restaurants with waiters, transforming the endogenous variable (y) according to the form $\ln (y+1)$, in order to avoid the nondetermination when $\mathrm{y}=0$. 
Table 1 Regression results

\begin{tabular}{llclll}
\hline $\begin{array}{l}\text { Type of } \\
\text { business }\end{array}$ & $\begin{array}{l}\text { Dependent } \\
\text { variable } \\
\text { (logarithms) }\end{array}$ & $\begin{array}{l}\text { Semi- } \\
\text { elasticity }\end{array}$ & $\begin{array}{l}\text { p } \\
\text { Value }\end{array}$ & $\begin{array}{l}\text { No of } \\
\text { observations }\end{array}$ & $\begin{array}{l}\text { No of } \\
\text { clusters }\end{array}$ \\
\hline Restaurant with & Revenues & 0.248 & 0.288 & 3432 & 66 \\
waiters & Wages & 0.282 & 0.298 & 2239 & 46 \\
& Employment & 0.162 & 0.225 & 2912 & 56 \\
Nightclubs, bars & Revenues & -0.015 & 0.914 & 884 & 17 \\
and pubs & Wages & 0.001 & 0.994 & 719 & 14 \\
& Employment & 0.030 & 0.552 & 832 & 16 \\
\hline
\end{tabular}

\section{RESULTS}

Table 1 presents results for the six models estimated. The semielasticity calculated based on the coefficient of $\mathrm{B}_{0}$, the difference between the treatment and counterfactual groups, is not statistically significant in any of the models. In the first model, which estimates the effect of the smoke-free law on revenues for restaurants with waiter service, the effect is 0.248 , suggesting that the implementation of the law is associated with a $24.8 \%$ increase in revenues after controlling for the other factors in the model. However, this effect is not statistically significant. The estimated effects on wages and employment are positive, $28.2 \%$ and $16.2 \%$, respectively. For nightclubs, bars and pubs the estimated effects are $-1.5 \%, 0.1 \%$ and $3 \%$ for revenues, wages and employment, respectively. None of these estimates is statistically significant.

The results can also be portrayed graphically. Figures 2 and 3 present a comparison of revenues in bars and restaurants (figure 2) and in pubs and nightclubs (figure 3), before and after the implementation of the Mexico City law. The graphs show visually what the regression results quantify after controlling for other factors-after adjusting for fixed effects, revenues decreased in the one year period from April 2008 and April 2009 in bars and restaurants and in pubs and nightclubs, in both Mexico City and the comparison areas-most probably as the effect of the economic crisis that affected Mexico during that time. The trends in Mexico City parallel those in the counterfactual areas and there is no temporal effect that would suggest a negative impact of the Mexico City law.

In order to examine possible confounding related to changes in underlying economic factors that might vary by state, we also estimated models including fixed effects and per capita GDP at the state level-a technique employed in similar studies. ${ }^{35} 36$ We did not include these variables in the final model as they did not have a statistically significant effect. Further data exploration shows that

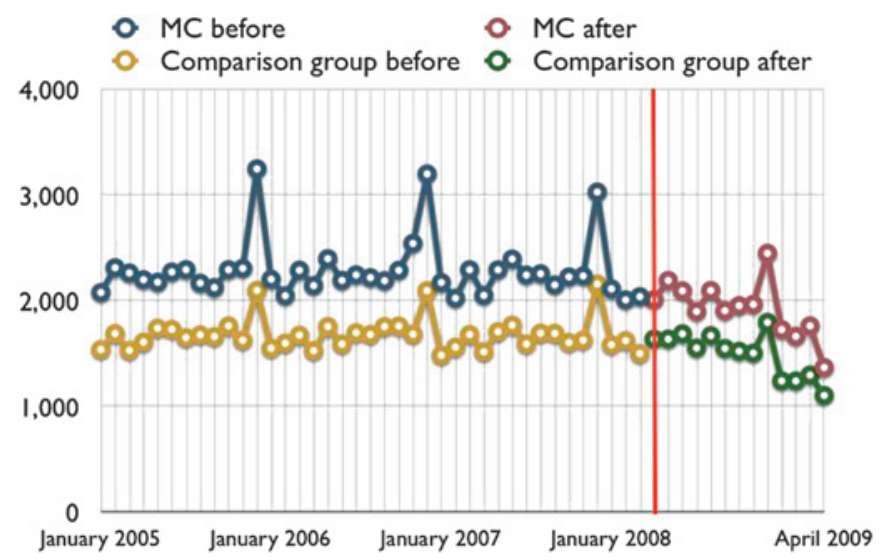

Figure 2 Average monthly revenues in restaurants, Mexico City (MC) and comparison group (thousands of April 2009 pesos). Source: Monthly Services Survey, National Institute for Statistics and Geography (INEGI).

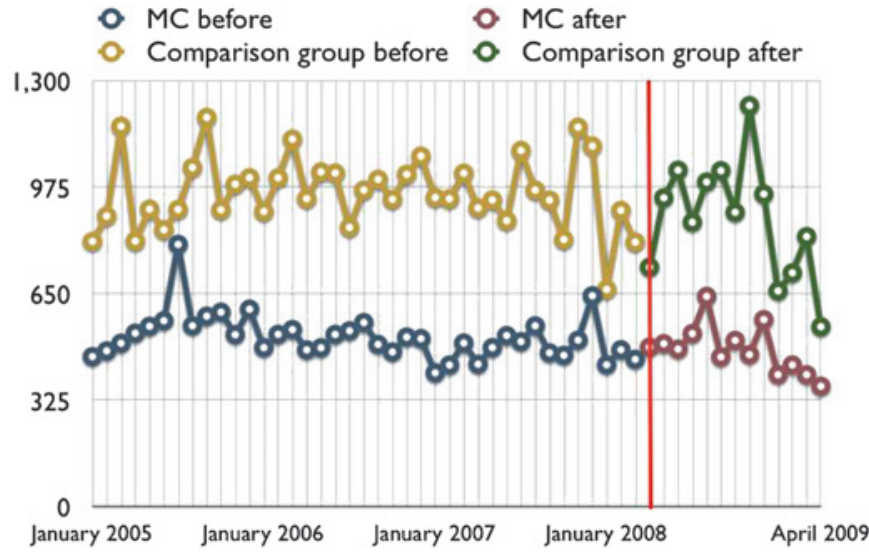

Figure 3 Average monthly revenues in pubs and nightclubs, Mexico City (MC) and comparison group (Thousands of April 2009 pesos). Source: Monthly Services Survey, National Institute for Statistics and Geography (INEGI).

changes in economic factors - including state GDP per capita-do not vary substantially over time within the states (figure 4, below).

We estimated separate regressions, with employment, wages and income as dependent variables, including among the independent variables separate linear time trends for employment, wages and income-separated by control and treatment group - to test for temporal variation in the impact of the fixed effects. This analysis showed no significant effects, rejecting the hypothesis that over time these factors have a differential impact on the outcome variables in the control and treatment groups. We also looked for additional state-level policies that might have influenced the outcomes and found none. Based on this analysis, we conclude that the fixed effects for the specific business $(\alpha)$ and time period $(\lambda)$ sufficiently capture these economic factors and their changes over time.

\section{DISCUSSION}

The results of models estimating the impact of the Mexico City law on revenues, wages and employment show that the implementation of the law did not have a statistically significant effect. These estimates are the result of a thorough modelling exercise-including testing different model specifications, none of which show a statistically significant negative effect of the law on revenues, wages or employment levels.

The assumption of effective (and consistent) implementation of the law is critical to our study. The Mexican National Institute of Public Health (INSP in Spanish) carried out research to measure the level of exposure to secondhand smoke in bars and restaurants, concluding that exposure levels in Mexico City were lower than in three other areas where measurements were taken (the states of Colima, Cuernavaca and Mexico). ${ }^{37}$ A separate study found that exposure to secondhand smoke in restaurants, bars and pubs decreased substantially following the implementation of the law. ${ }^{38}$ These studies support the conclusion that the Mexico City smoking ban has in fact been effectively implemented.

Our findings are compatible with an increasing collection of studies that have studied the economic effects of smoking restrictions on the hospitality industry, as described in the introduction to this paper. Studies in Canada, New Zealand, Hong Kong, Scotland, South Africa and several states in the USA have all shown that smoke-free laws do not harm the economic interests of the restaurant and bar industries on an aggregate basis. This study adds significantly to the existing findings, using 


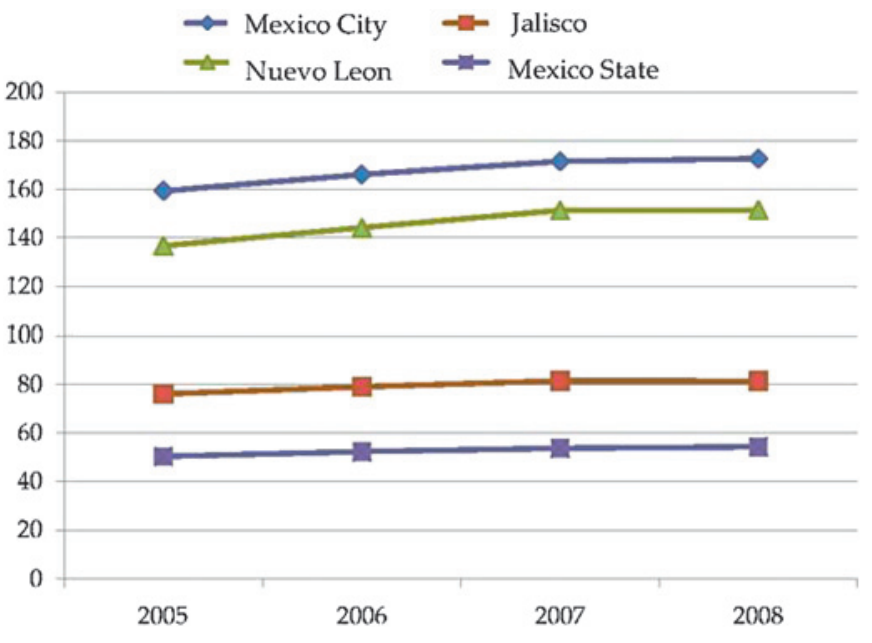

Figure 4 Per-capita GDP in the states analysed (thousands of 2003 pesos). Source: National Institute for Statistics and Geography (INEGI).

a large and statistically representative database and more than one year of data following the implementation of the smoking ban. It is the first comprehensive study of its type conducted in Latin America. However, there are some limitations to the analysis. We do not have access to information on taxes paid by specific businesses, for example, which other analyses have used as a direct measure of economic activity. ${ }^{39} 40$ Also, the sample used to collect data for the Monthly Services Survey is small and is statistically representative only at the national level, not by state. However if the Non-Smokers' Health Protection Law had indeed significantly negatively affected revenues, wages or employment levels in Mexico City, our methods would have been able to detect these effects.

An important strength of this study is that it uses three different measures of economic wellbeing in the hospitality industry-revenues, wages paid and levels of employment. Furthermore, the data are collected by an independent government body and cover an extensive period of time-39 monthly observations prior to the implementation of the law and 13 monthly observations afterwards. The study takes advantage of a natural experiment for the period of time in which the Mexico City law had been applied, but the national law had not yet taken effect.

In several countries where smoking bans have been implemented, there remain questions about the adequacy of the enforcement of these laws. In Mexico, available evidence suggests the law in Mexico City has been effectively implemented. At the national level, the General Law for Tobacco Control, which requires smoke-free bars and restaurants throughout the country, was passed in May 2008. In August 2008 the regulatory mechanisms for the law were approved.

Other sources of information show that the majority of the population supports laws restricting smoking in closed public places and in workplaces. A 2007 survey found that $80 \%$ of the population-including $71 \%$ of smokers-of the Federal District were in agreement with the passage of smoke-free laws for public places. ${ }^{41}$ On the other hand, a poll conducted by the National Institute of Public Health before and after the implementation of the law, found that most Mexico City inhabitants were supportive. In March 2008, 80\% supported the law in restaurants. In December 2008 this percentage had increased to $93 \%$. In bars the findings are similar-61\% supporting before implementation and $71 \%$ afterwards. ${ }^{42}$

\section{What is already known on this subject}

Smoke-free environments protect the health of non-smokers and workers in the hospitality industry, and also contribute to decreasing the social acceptability of smoking and the consumption of active cigarette smokers. There has been some controversy about whether these measures have negative economic effects on the industry-specifically on restaurants, bars and nightclubs. Studies in other countries have concluded that the implementation of smoke-free environments does not reduce revenues overall for these types of businesses.

\section{What this study adds}

Mexico City implemented smoke-free legislation April 2008. This study is the first to evaluate the economic impact of the law, using a detailed dataset and appropriate econometric techniques. The study provides timely information for tobacco control efforts in Mexico and adds to the scarce literature on the economic impact of smoke-free laws in low and middle-income countries.

\section{CONCLUSION}

The results of this study show clearly that-with more than one year of data following the implementation Mexico City's NonSmokers' Health Protection Law-the law has not had a negative effect on revenues, wages and employment levels in the businesses affected by the law, including restaurants, nightclubs, bars and taverns. The models use a differences-in-differences methodology and fixed effects to control for characteristics specific to individual businesses. In addition to the principal findings, the study shows the benefits of developing and maintaining information systems that allow for the collection for detailed economic data by type of activity and geographic area-in order to be able to effectively evaluate public policies.

This finding is consistent with results from similar studies carried out in other countries and settings globally. Legislation requiring smoke-free public places does not have a negative economic effect on the restaurant and bar industry. Given that these laws do have a positive effect in terms of reducing exposure to secondhand smoke and in the long run reducing smoking prevalence and the social desirability of smoking, there is a great deal of evidence suggesting that they form a positive and essential component of tobacco control strategies. ${ }^{43}$ These results provide scientific evidence to policymakers and legislators in Mexico and in other countries to impel local laws that promote $100 \%$ smoke-free public places in order to fulfil the provisions of the Framework Convention on Tobacco Control.

Funding This study was supported by the Bloomberg Global Initiative to Reducing Tobacco Use. The authors are grateful for the collaboration of officials of the Mexican National Institute for Statistics and Geography (INEGI) and specifically Eng Ramón Bravo Zepeda, Deputy Director of Surveys and Services in the General Direction of Economic Statistics; Eng Juan José Ríos Franco, Director of Statistics for the Tertiary Sector; and Lic Jorge Alberto Reyes Moreno, Adjunct Director for Economic Surveys and Administrative Registration. We are also grateful for constructive comments from two external reviewers.

\section{Competing interests None.}

Contributors CG and JJ had principal responsibility in designing the study and collecting data. CG, JJ and HW had primary responsibility in writing the manuscript. HW provided technical oversight for the study. LMR oversaw the implementation of 
the study and data collection. All four of the authors were involved in the data analysis and interpretation.

Provenance and peer review Not commissioned; externally peer reviewed.

\section{REFERENCES}

1. The Health Consequences of Involuntary Exposure to Tobacco Smoke: A Report of the Surgeon General. Atlanta, GA: Office on Smoking and Health, Centers for Disease Control and Prevention, 2006.

2. Parties to the WHO Framework Convention on Tobacco Control: WHO Framework Convention on Tobacco Control. http://www.who.int/fctc/signatories_parties/en/index.html.

3. Guidelines on Protection from Exposure to Tobacco Smoke: WHO Framework Convention on Tobacco Control. http://www.who.int/fctc/cop/art\%208\% 20guidelines_english.pdf.

4. Evans MK. The Economic Impact of Smoking Bans. Ottawa, London, Kingston: Kitchener, Ontario. Evans, Carroll \& Associates. http://www.tlw.org/public/content/ Documents/Smoking\%20Ban/Evans\%20Report\%20Summary\%20\%28Canada\%29.pdf.

5. Tavern League of Wisconsin. Economic Impact of Smoking Bans. http://www.tlw.org/ public/content/Documents/Smoking\%20Ban/Economic Impacts.pdf

6. NSW clubs record worst financial result ever. The indoor smoking ban has been blamed for a $\$ 385$ million fall in income by NSW clubs, their worst result ever. The Australian, 2008. http://www.theaustralian.com.au/news/smoking-ban-deals-clubs385m-loss/story-e6frg6o6-1111117079860?from=public rss.

7. Simpson D. Smoke-free laws do not harm profits: new global report. Tob Control 2005;14:220.

8. Scollo M, Lal A, Hyland A, et al. Review of the quality of studies on the economic effects of smoke-free policies on the hospitality industry. Tob Control 2003;12:13-20.

9. Luk R, Ferrence R, Gmel G. The economic impact of a smoke-free bylaw on restaurant and bar sales in Ottawa, Canada. Addiction 2006:101:P738-45.

10. Thomson G, Wilson N. One year of smokefree bars and restaurants in New Zealand: Impacts and responses. BMC Public Health 2006;6:64-73.

11. Lam TH, Janghorbani M, Hedley AJ, et al. Public opinion on smoke-free policies in restaurants and predicted effect on patronage in Hong Kong. Tob Control 2002;11:195-200.

12. Lal A, Siahpush M, Scollo M. The economic impact of smoke-free legislation on sales turnover in restaurants and pubs in Tasmania. Tob Control 2004;13:454-5.

13. Adda J, Berlinski S, Machin S. Short-run economic effects of the Scottish smoking ban. Int J Epidemiol 2007;36:149-54.

14. Alamar BC, Glantz SA. Smoke-free ordinances increase profit and value restaurant. value. Contemp Econ Policy 2004:22:P520-5.

15. Glantz SA, Smith LRA. The effect of ordinances requiring smoke-free restaurants and bars on revenues: a follow-up. Am J Public Health 1997;87:1687-93.

16. Cowling DW, Bond P. Smoke-free laws and bar revenues in California - the last call. Health Econ 2005;14:1273-81.

17. Glantz SA. Effect of smokefree bar law on bar revenues in California. Tob Control 2000:9:P111-13.

18. Sciacca JP, Ratliff IM. Prohibiting smoking in restaurants: effects on restaurant sales. Am J Health Promot 1998:12:176-84.

19. Bartosch WJ, Pope GC. Economic effect of smoking restrictions on restaurant business in restaurant Massachusetts, 1992-1998. Tob Control 2002;11(Suppl II):ï38-42.

20. American Cancer Society/UICC. Smoke-Free Air: The Essential Facts. Enacting Strong Smoke-Free Laws: The Advocate's Guide to Legislative Strategies. Atlanta, GA: The American Cancer Society, 2006.

21. Hyland A, Cummings KM, Nauenberg E. Analysis of taxable sale receipts: was New York What city's smoke free air act bad for restaurant business? J Public Health Manag Pract 1999;5:P14-21.

22. International Agency for Research on Cancer, World Health Organization. Evaluating the Effectiveness of Smoke-free Policies. Evaluating the Effectiveness of
Smoke-free Policies. Vol 13: IARC Handbook of Cancer Prevention, Tobacco Control, 2009. http://www.iarc.fr/en/publications/pdfs-online/prev/handbook13/handbook13. pdf.

23. Blecher EH. The effects of the tobacco products control amendment act of 1999 on restaurant revenues in South Africa: a panel data approach. S Afr J Econ 2006; 74:123-30.

24. Van Walbeek CP, Blecher EH, Van Graan M. The Effects of the Tobacco Products Control Amendment Act of 1999 on restaurant revenues in South Africa: a survey approach. S Afr Med J 2007:97:208-11.

25. National Institute for Statistics and Geography. Economic Census. Website (in spanish): http://www.inegi.org.mx/est/contenidos/espanol/proyectos/censos/ ce2004/cuadrosce04 .asp?c=10371 \&s=est Consulted 20 0ct 2010.

26. Ley de Protección a la Salud de los No Fumadores en el Distrito Federal (Law for Health Protection of Non-Smokers in the Federal District). Published in the Official Gazette of the Federal District, January 29 2004, with the last change on March 4, 2008

27. Dearlove JV, Bialous SA, Glantz SA. Tobacco manipulation of the hospitality industry to maintain smoking in industry public places. Tob Control 2002;11:94-104.

28. General Law for Tobacco Control. Official Diary of the Federation. Mexico City: Government of Mexico, 2008.

29. General Law for Tobacco Control. Official Diary of the Federation. Mexico City: Government of Mexico, 2010.

30. Angrist JD, Pischke JS. Mostly Harmless Econometrics: an Empiricist's Companion Princeton, NJ: Princeton University Press, 2009

31. Bertrand M, Duflo E, Mullainathan S. What How much should we trust differences in differences estimates? O J Econ 2004:119:249-75.

32. Analysis of the National Addictions Survey (Encuesta Nacional de Adicciones) 2008 Primera Edición, Febrero. Mexico City: Government of Mexico, 2009. http://insp.mx/ Portal/Inf/encuesta_adicciones08.php.

33. National Institute for Statistics and Geography. Mexico City: Government of Mexico. Website (in Spanish). http://www.inegi.org.mx.

34. Official Diary of the Federation. Mexico City: Government of Mexico, 2009

35. Scott A, Chad D. The effect of smoking bans on bars and restaurants: An analysis of changes in employment. The B.E. Journal of Economic Analysis and Policy 2007:7 (Contributions), Article 12.

36. Kaplan D, Piedra E, Seira E. Are Burdensome Registration Procedures an Important Barrier on Firm Creation? Evidence from Mexico: Centro de Investigación Económica, 2007:7-1. Discussion Paper.

37. Barrientos-Gutiérrez T. Ventilation, Air Extraction or Smoking Ban? Environmental Tobacco Smoke Exposure in Mexican Restaurants and Bars. Mexico: National Institute for Public Health, 2008.

38. Thrasher JF, Pérez-Hernández R, Swayamkapala K, et al. Policy support, norms, and secondhand smoke exposure before and after implementation of a comprehensive smoke-free law in Mexico City. Am J Public Health 2010;100:1789-98.

39. Hyland A, Cummings KM, Nauenberg E. Analysis of taxable sale receipts: was New York city's smoke free air act bad for restaurant business? J Public Health Manag Pract 1999;5:14-21.

40. Hyland A, Vein C, Cummings KM, et al. The effect of the clean air act of Erie county, New York restaurant on employment. J Public Health Manag Pract 2000;6 76-85.

41. Parametría and the Mexican Council against Tobacco. Executive Report on Smokefree Spaces. Mexico: Mexican Council against Tobacco, 2007.

42. National Institute of Public Health. Impactos sociales, ambientales y económicos de los espacios 100\% libres de humo de tabaco. Mexico: El caso de la Ley de Protección a la Salud de los No Fumadores, Distrito Federal, México, 2009.

43. Wollery T, Asthma S, Sharp D. Clean indoor-air laws and youth access restrictions In: JHA P. Chaloupka F, eds. Tobacco Control in Developing Countries. Washington, DC: Oxford University Press, 2000:273-86. 